\title{
Amerika
}

Mémoires, identités, territoires

15 | 2016 :

Coup d'état en Argentine et Guerre des Malouines

Dossier "Coup d'état en Argentine et Guerre des Malouines"

Coup d'État : militaires, résistants et artistes

\section{Los quiebres del recuerdo: entre democracia y dictadura en la Argentina}

\section{Máximo Hernán Mena}

\section{Resúmenes}

Español English

¿Cómo hablar de una ciudad que se despelleja su propio pasado? La escritura de El día que mataron a Bussi (2000), segunda novela de Ernesto Wilde (1950-2011), establece un recorrido pendular entre la historia, el testimonio y la ficción. Los sucesos se resisten a ser narrados. ¿Cómo se explica que en la provincia de Tucumán se elija como gobernador en democracia a Antonio Domingo Bussi? Si se tiene en cuenta que fue acusado y luego condenado por delitos de lesa humanidad cometidos antes y durante la dictadura militar del "Proceso de Reorganización Nacional". ¿De qué manera es posible reconocer los límites entre dictadura y democracia?, si la violencia y la tortura ya eran ejercidas en la provincia de Tucumán, durante el "Operativo Independencia" de contrainsurgencia que se inició en febrero de 1975, con anterioridad al último Golpe de estado del 24 de marzo de 1976. Por lo tanto, en este trabajo se propondrá un estudio interdisciplinario que contemple la articulación de los discursos ficcionales e históricos.

How do we speak about a city which denies its own past? The writing of El día que mataron a Bussi (2000), the second novel of Ernesto Wilde (1950-2011), proposes a pendulous tour between history, testimony and fiction. The events refuse to be narrated. Is it possible to explain how Antonio Domingo Bussi was elected to be Tucuman's governor during a democracy, considering that he was accused of acts of genocide and then condemned for the human rights's violations committed before and during the military dictatorship of the "Proceso de Reorganización Nacional" ? How is it possible to recognize the limits among 
dictatorship and democracy if violence and torture already were implemented in Tucuman, during the "Operativo Independencia" that began in February 1975, before the last Coup d'état of 24th March 1976 ? Therefore, this work will propose an interdisciplinary study that contemplates the coincidences and visible contrasts of fictional and historical discourses.

\section{Entradas del índice}

Mots-clés : Argentina, Tucumán, ficción, dictadura, Operativo Independencia Keywords : Argentine, Tucuman, fiction, dictatorship, Operativo Independencia Geográfico : Latinoamérica, República Argentina, Tucumán

\section{Texto completo}

Lo peor de la muerte es también que nada sigue igual, que quién se fue nunca volverá ni nos verá ni nos tomará la mano o nos hablará como alguna vez creímos. (Ernesto

\section{Breve introducción : Tucumán antes de marzo del espanto}

Casi el cuarenta por ciento de las desapariciones de personas (registradas) en Tucumán se produjeron antes del 24 de marzo de 1976. Y a pesar de que este día es una marca indeleble en la historia argentina, en ocasiones la mención solitaria de la fecha, como inicio del terror o del terrorismo de estado en la Argentina significa un borramiento rotundo, una atenuación demasiado accesible y poco esclarecedora. La problemática de los límites y de los supuestos orígenes siempre conduce a otras cuestiones más interesantes, como la de los puntos de continuidad entre ciertas prácticas sociales o los modos en que los procesos históricos diluyen las cronologías. En este sentido, el caso de la provincia de Tucumán resulta emblemático y los registros son claros al respecto : de los 656 desaparecidos (que representan un «subregistro») en la provincia de Tucumán

239 casos se produjeron antes del golpe del 24 de marzo y 410 después, más un pequeño número sin fecha determinada. Los 239 representan el $36.6 \%$ del total de desaparecidos en Tucumán a lo largo de los años ' 70 : 9 en 1974, 145 en $1975 ; 85$ entre enero y marzo de 1976. (Pucci, 2009:248)

En este sentido, entre 1974 y 1975 se crean en Tucumán los primeros Centros Clandestinos de Detención (CCD) ${ }^{1}$ de la historia argentina ${ }^{2}$. Luego de la muerte de Juan Domingo Perón en 1974, quedó a cargo de la presidencia su mujer, María Estela Martínez de Perón, quien en un Decreto secreto del 5 de febrero de 1975 declara el inicio del "Operativo Independencia" con el que se buscaba «neutralizar y/o aniquilar» la "amenaza subversiva» que operaba en los cerros tucumanos (San Martino de Dromi, 1988 : 108, tomo dos). Sin embargo, los únicos alcanzados por esta orden de exterminio, emanada por un gobierno constitucional y democrático, no fueron solamente los comandos del ERP (Ejército Revolucionario del Pueblo), sino también numerosos civiles, intelectuales, dirigentes sindicales, políticos, 
estudiantes. Lo que se pone en marcha es el comienzo de un operativo de exterminio que luego se va extender a todo el país con la dictadura del "Proceso de Reorganización Nacional”. Asimismo, es necesario destacar que, con anterioridad y desde el 6 de noviembre de 1974, por decreto 1368 de la Presidenta Martínez de Perón, se declaró el Estado de sitio en todo el país. Situación que se prolongó hasta la asunción del presidente Raúl Alfonsín (1988 : 57-58). En este sentido, el Informe de la Comisión Bicameral ${ }^{3}$ en Tucumán, que asienta las investigaciones de violación a los derechos humanos en la provincia, destaca los crímenes de lesa humanidad cometidos desde ese mismo 6 de noviembre de 1974 en la provincia (cfr. Informe de la Comisión Bicameral Investigadora de los Derechos Humanos en la Provincia de Tucumán. 1974-1983 (1991)4.

3 De este modo, el llamado "Operativo Independencia" es el complemento exacerbado del "Operativo Tucumán”, iniciado en 1966 por la dictadura de la "Revolución Argentina” y que significó el desmantelamiento de la estructura productiva azucarera con el cierre definitivo de once de los veintisiete ingenios azucareros que estaban en funcionamiento ${ }^{5}$. Las consecuencias más directas de este decreto firmado por Juan Carlos Onganía se revelaron en el éxodo masivo de más de 250.00o tucumanos y en el alto desempleo que llevó a muchas familias a quedar en la indigencia ante la falta de trabajo. A partir de esta situación, se produjeron en Tucumán numerosas protestas sociales y tres levantamientos conocidos como “Tucumanazos" en los años 1969, 1970 y $1972^{6}$.

En referencia con lo señalado hay que destacar que la obra ficcional de Ernesto Wilde ${ }^{7}$ y de numerosos autores tucumanos ${ }^{8}$ se puede leer como un intento lúcido por hacer visibles estos quiebres en la historia y la memoria y por plantear la incertidumbre dominante al reflexionar acerca de las continuidades entre dictadura, democracia, autoritarismo y populismo. El caso de la obra de Ernesto Wilde es paradigmática ya que aborda estas problemáticas y, en El día que mataron a Bussi (2000), se dedica a recrear las representaciones sociales sobre la figura de Antonio Domingo Bussi ${ }^{9}$ para cuestionar el funcionamiento de la memoria y el olvido en la historia reciente de Tucumán y del país y, por lo tanto, los vínculos y tensiones entre la ficción, la historia y la memoria. El 20 de diciembre de 1975, Bussi asume el comando del "Operativo Independencia" en la provincia de Tucumán y, con posterioridad, en 1987, Bussi se presenta por primera vez a elecciones democráticas y es elegido Diputado nacional. Al año siguiente funda su propia partido, Fuerza Republicana, y en las elecciones de 1991 se presenta como candidato a gobernador y es derrotado por un estrecho margen por el cantante Ramón "Palito" Ortega. Sin embargo, al triunfar en las elecciones provinciales de 1995 es proclamado gobernador de la provincia. La trayectoria militar y política de Bussi es un muestra decisiva acerca de las paradojas y contradicciones de la sociedad tucumana y también de la Argentina en su conjunto. A partir de su reaparición como político se complejizan aún más las dinámicas de la memoria colectiva y del olvido, mecanismos en tensión constante que se ponen en juego en la ficción y en las investigaciones históricas.

5 Por lo tanto, en este trabajo se analizarán las «huellas» y las marcas presentes en la ficción que permiten reconstruir diversas intertextualidades y cruces con los discursos de la historia reciente y de la memoria de la sociedad tucumana. Asimismo, el trabajo con las entrevistas a autores e investigadores aporta otras miradas y conceptos acerca de lo sucedido. De esta manera, la reflexión acerca de Tucumán permite ampliar y profundizar la discusión acerca de los procesos históricos en la Argentina y las dinámicas autoritarias y represivas exacerbadas a 
partir de la puesta en marcha del llamado "Proceso de Reorganización Nacional”.

\section{Entre el recuerdo y la escritura}

¿Cómo se comienza a hablar de la violencia y de la muerte? ¿De qué manera se recuerda el olvido en los rostros de los otros? ¿Cómo conversar con una ciudad que se despelleja su propio pasado? La novela El día que mataron a Bussi (2000), de Ernesto Wilde, incluye un breve texto en el que se refiere : «Como el lector entenderá, los personajes y acontecimientos de esta novela son sólo ficción» (Wilde, $2000: 10$ ). Este gesto funciona como punto de partida y, simultáneamente, como como punto de fuga que se refuerza a partir de la inclusión de un paratexto titulado «Amigo lector» $\mathrm{y}$ firmado por el mismo autor:

Concluí esta novela alrededor de noviembre de 1998. [...] El texto, que me demandó pocos meses de escritura más tensa que placentera, surgió de una necesidad casi hepática de responderme a preguntas que me acosan desde hace años. Y también provino de una pesadilla, una pesadilla que me angustió tanto que no encontraba sosiego. [...] Algunas de esas preguntas eran : ¿ंPor qué los tucumanos votan a Bussi? ¿Por qué una sociedad multifacética de lucha y emprendimientos viriles, que creció con fuerza merced a la riqueza de su tierra y al ingenio de su gente, hoy se convirtió en un pueblo pasivo que acepta, con irreparable resignación, su destino de pobreza y angustia? [...] Tomé el caso Bussi porque me resultan hondamente perturbadoras y conflictivas esas preguntas. Pero el verdadero protagonista es Tucumán. No estoy inventando lo ocurrido.

Si no tuviéramos la responsabilidad de dar cuenta de tanta corrupción e ilusiones robadas, podríamos esquivar la función testimonial. Pero las cosas, en general, no son como uno quiere. (Wilde, 2000 : 7-8)

Así se instaura un «espacio que antecede a la obra» y genera una «estética de lo inminente» : «la manera propia en que la literatura se posiciona en la sociedad : no tanto ante lo que es como ante lo que no es o lo que podría ser» (García Canclini, 2014 : 75). El comienzo de la novela es un lugar de paso, un espacio que abre lo que está por llegar, lo que será dicho o afirmado en la historia de un lenguaje, que urde un espacio de tránsito, una «zona incipiente» que permite a la novela hacer preguntas que otros discursos no se formulan (2014: 76). Los interrogantes del autor se duplican a la largo de la novela y se transmutan en las búsquedas y preguntas del personaje Howard Globe, que funciona como alter ego. Al igual que en la primera novela de Ernesto Wilde, Saldos y retazos (1993), el protagonista es un periodista. En este caso, Howard Globe es un periodista extranjero que ha llegado a Tucumán para cubrir la noticia del asesinato del entonces gobernador Antonio Domingo Bussi. Globe observa y escribe como extranjero, «desinstalándose de lo habitual» (García Canclini, $2014: 17$ ). Al igual que los historiadores que describe Marc Bloch, Globe sabe que los documentos o los testigos «no hablan sino cuando se sabe interrogarlos», intenta mirar en el presente, «captar lo vivo» del hoy, procura descubrir, en los documentos o palabras, «huellas» que hablen sobre los sucesos (Bloch, 2000 : 47-58). No puede regresar al momento del asesinato y debe contar con los testimonios que son como «señuelos», convocan nuevas miradas y voces : «Toda información sobre cosas vistas está hecha en buena parte de cosas vistas por otro» (2000: 52 ).

A partir del relato polimórfico y cambiante, el lector-oyente debe reconocer la 
lectura de la ficción como una actividad y reconocerse como una "persona que inventa activamente un objeto» (Bajtín, 1989 : 64). A la amplia inclusión de otros discursos en la novela le sigue un uso lúdico y reflexivo de las convenciones ficcionales que genera vacilaciones en la lectura porque : ¿̇cómo se corresponde esa decisión de no inventar lo ocurrido con la afirmación del relato como sólo ficción?. La novela permanece en un espacio medio, en esta inminencia, en un área indeterminada y permeable que reescribe, reafirma, pero oculta de nuevo y renuncia a un posible discurso histórico. La ficción es una coartada para narrar otra historia, encarnar los conflictos y dar vida a las dudas en los destinos de los personajes.

Hay que destacar entonces que el testimonio y, por lo tanto, el recuerdo, se construyen en el marco de un grupo que le brinda un sostén y lo constituye en una práctica de rememoración ; en una acción del pensar y recordar activamente. Así, el testimonio se erige en una «institución natural de vinculación» (Ricoeur, 2008 : 211214), que por un lado, asevera la realidad de lo sucedido y, al mismo tiempo, procura autentificar la declaración (2008 : 211). Este primer elemento, problematiza, como lo señala el mismo Ricoeur, la distinción entre realidad y ficción, a partir de esta frontera indecidible planteada por el testimonio en la que «surgen numerosas sospechas» (2008 : 211). Así también, el testimonio se realiza a partir de la «autodesignación del sujeto» que asegura "yo estaba allí», al mismo tiempo que reafirma la realidad de lo sucedido. A su vez, este testimonio asume la figura de un diálogo, de una conversación entre varios interlocutores, lo que refuerza la validez de lo afirmado (2008 : 212). ¿Es posible el testimonio a través de la ficción? Quizás la ficción es una máscara para defender la palabra, insinuar los hechos y escapar, nuevamente, de la represión, a través de una fuga entre las convenciones.

También es preciso señalar que en el momento de la escritura de la novela, Bussi era gobernador democrático de la provincia. A su vez, es preciso recordar que, en mayo de 2004, Bussi le había iniciado una demanda por calumnias e injurias al escritor Tomás Eloy Martínez por escribir sobre sus acciones asesinas, que finalmente fue rechazada. Es en este contexto en el cual se comprende mucho más el recurso del método ficcional para contar otra historia. Enmarcar la duda en la ficción le permite aludir de forma encubierta a ciertos hechos y personajes de la realidad de ese presente. Por lo tanto, ese gesto busca generar una empatía en los lectores, una suerte de reconocimiento reflexivo porque la realidad persigue la escritura como una espiral sin fin.

\section{Los sueños, las pesadillas y la realidad de la muerte}

En muchas ocasiones, la ficción puede ser más verdadera que la "verdad", los sueños o las pesadillas pueden hablar más claro sobre lo real que lo que ven los ojos en la vigilia : «Se puede crear un discurso imaginario sobre acontecimientos reales que puede ser no menos "verdadero" por el hecho de ser imaginario" (White, 1992 : 74). En la novela de Wilde, la vacilación generada respecto a lo histórico y lo real se refuerza con la duda de los personajes sobre lo indefinido de los límites entre la vigilia y las pesadillas.

La principal conclusión que saco de mi experiencia en Tucumán es ésta : ¿̇y si

Bussi hubiera simulado ser, justamente, Antonio Domingo Bussi? ¿O, a la

inversa, si los tucumanos estuvieran condenados a soñar que Bussi existió 
realmente y se reproduce en su vástago?(Wilde, 2000 : 19-20)

La historia, la ficción, las pesadillas y lo real se entrecruzan de muchas maneras. Según Wilde, en Tucumán la realidad enrarece y difumina todo. A través de su alter ego, el periodista extranjero Howard Globe, y de la supuesta ficcionalidad, Wilde retrata espacios oscuros de la ciudad real y consigue entrelazar hechos y personajes significativos de la historia. Globe no sabe para que está allí, a nadie le interesa el crimen, todos lo han olvidado, todos han borrado una parte de sus vidas con el asesinato y duermen más tranquilos : «tal vez los tucumanos están condenados a creer (o fingir que creen) que Bussi existió y fue asesinado, no sé a esta altura...» (2000 : 33). ¿Y si Bussi fue una pesadilla? Pero todo ha sido real ; porque los muertos no despiertan.

Yo humanamente quisiera creer que hemos tenido el siniestro sueño de soñarlo. Lo terrible de Bussi, casualmente es la sensación de lo siniestro, para mí en el sentido más ominoso, más profundo de la palabra. Porque la verdad que el trabajo más sucio lo hizo Adel Vilas, tan asesino como Bussi, quien después vino a perfeccionar el trabajo. ¿Qué es lo que lo convierte a Bussi en un personaje que tiene un plus con relación a los otros? Bussi se reacomoda en los pliegues de la democracia argentina. [...] Bussi es el siniestro que logra mimetizarse en el momento democrático. [...] Esto es lo siniestro, no solamente Bussi, sino quienes lo produjeron. En ese caso Tucumán es revelador, Tucumán es una vanguardia, revela lo positivo y lo negativo, en este caso lo más negativo. ${ }^{10}$

\section{Los estragos de la violencia}

Desde el punto de partida de 1966 y con la puesta en marcha del "Operativo Tucumán" durante la autodenominada "Revolución Argentina”, se inicia el proceso de desmoronamiento de toda una provincia : «licuefacción» de la estructura productiva y desgarramiento de los vínculos sociales. El proyecto de la "Revolución Argentina” se inicia con la decisión de devastar la provincia de Tucumán:

Muy pocos recuerdan hoy que, para justificar la instauración de aquella dictadura militar, los protagonistas del golpe de 1966 alegaron como uno de sus motivos principales la necesidad de terminar de una vez y para siempre, con lo que el país entero denominaba como el "problema tucumano". (Pucci, 2007 : 18-19)

La situación producida por este desmantelamiento e intervención violenta derivó en un proceso de resistencia social que se prolongó hasta la década del '70. Con la puesta en marcha del "Operativo Independencia", se iniciaba la segunda intervención sobre el cuerpo de la provincia, y a través de este operativo se buscaba eliminar del territorio tucumano la amenaza de «infiltración marxista».

Cuando me preguntas por el "Operativo Independencia", que es una especie de prólogo al golpe de estado del 24 de marzo de 1976, el país se desliza hacia el terrorismo de estado, hacia la conversión del Estado en un aparato criminal, sin principios, cruel, perverso, no solamente en manos de los militares sino también en manos de todos los civiles que los acompañaron. Fueron años de plomo, un túnel oscuro en el que ingresamos todos los argentinos, los que se tuvieron que ir, los que murieron, los que se quedaron. En casi una década murió lo que hasta entonces se había vivido, desapareció lo que hasta entonces se había vivido, es decir, ese alto grado de movilidad social, de protagonismo, ese momento donde había muchos partidos, momento de movimientos 
estudiantiles, de sindicalismo rebelde, de esa intelectualidad en efervescencia.

Todo esto fue sustituido por el silencio y por la muerte.11

$\mathrm{Al}$ frente del "Operativo Independencia”, en un primer momento estuvo el militar Adel Vilas, luego, en diciembre del mismo año 1975, será reemplazado por el general Antonio Domingo Bussi. Con el golpe de estado del 24 de marzo de 1976, cuando Jorge Rafael Videla ${ }^{12}$ asume la presidencia de facto, nombra a Antonio Bussi como jefe militar de la región y gobernador de facto de la provincia de Tucumán. Es así que en la provincia de Tucumán se registra, a diferencia de otras partes del país, la confluencia del control del poder político y del poder militar en la persona de Bussi, ya que en otras partes del país se estableció «una relativa dualidad» entre el jefe militar y el gobernador militar (Crenzel, 2001 : 19). Además, desde mucho antes del 24 de marzo y con la «anuencia» del gobernador justicialista de Amado Juri ${ }^{13}$, Bussi controlaba todo el territorio provincial lo que tornó «aún menos perceptibles las diferencias entre la ferocidad que asumían los enfrentamientos políticos en el final del gobierno peronista y la dictadura que emergía» (2001:19).

Así aparece en escena la figura de Antonio Domingo Bussi. Antes de entregar el mando, Adel Vilas aseguraba que la lucha contra el subversivo había terminado el 25 de octubre de 1975 con el combate de San Gabriel y en enero de 1976, Jorge Videla, como Jefe del Ejército, afirmaba que la situación en Tucumán estaba «controlada» (Pucci, 2009 : 242-243). La supuesta "guerra" contra los comandos "guerrilleros" y "subversivos» nunca lo fue y el número de fuerzas del ERP no llegó a superar los 100 individuos contra las fuerzas del Ejército que oscilaron entre los 2.500 y 6.000 efectivos (2009 : 237). Los mismos datos y hechos son narrados al comienzo de la novela de Wilde en una «Noticia preliminar» que sólo incluye un dato ficcional : la muerte de Bussi el 24 de marzo de 1999.

La represión ya había comenzado en Tucumán en 1974 con la formación de «grupos de tareas» integrados por civiles, militares y personal de inteligencia bajo las órdenes de los comisarios Albornoz e Hidalgo (Pucci, 2009 : 246). También tuvieron un importante papel organizaciones como la Alianza Anticomunista Argentina (Triple A) que actuó desde 1974 en la provincia y luego en conjunto con el Ejército durante el "Operativo Independencia" ; el "Comando Nacionalista del Norte" (filiación del lópezreguismo) ; y la Acción Revolucionaria Antimarxista (ARA) (2009 : 249-251). De este modo la llamada "peste de la subversión» se extendía sobre toda la ciudad, sobre cada uno de sus habitantes, la «subversión adquirió la dimensión de un demonio ubicuo y universal» (Pucci, 2009 : 243). Para encontrar las «fuentes de la subversión» era preciso llegar hasta la intimidad y las profundidades de los cuerpos, hasta cada uno de los individuos. En los «procedimientos antisubversivos» en Tucumán se pudieron identificar ciertas constantes:

1. 9 de cada 10 personas, fueron secuestradas en sus domicilios, lugares de trabajo o en la vía pública, por personas armadas, las que siempre actuaban en una superioridad numérica de 15 -aproximadamente- contra 1.

2. Los secuestradores, a veces uniformados, otras de civil, generalmente ocultaban sus rostros para asegurar su impunidad.

3. Operaban con gran despliegue de vehículos, sin chapas patentes o con las mismas adulteradas y siempre en un marco de absoluto desparpajo, llegando muchas veces a interrumpir el tráfico en varias cuadras a la redonda.

4. En la gran mayoría de los casos, estas acciones se desarrollaron en horas de la noche. (ICB, $1991: 22)$

El Informe de la Comisión Bicameral menciona los lugares empleados por las 
fuerzas represivas como Centros de Detención Clandestinos, identifica diecisiete de ellos y los divide en «chupaderos» o lugares de tránsito y «campos de concentración» en los que los detenidos permanecían más tiempo (ICB, 1991 : 9697). Entre los campos de concentración paradigmáticos figuran : "La Escuelita", campo ubicado en la Escuela Diego de Rojas (nombre del primer conquistador español que llegó a tierras del Tucumán...), en la localidad de Famaillá al suroeste de la capital ; los predios de la "Escuela de Educación Física", hoy Facultad de Educación Física de la Universidad Nacional de Tucumán ; entre otros (ICB, 1991 : 96). Como una marca fundamental, y de acuerdo a lo que señala Roberto Pucci, hay que destacar que la UNT es el centro universitario que registra el mayor número de desaparecidos en el país. También la UTN-FRT (Universidad Tecnológica Nacional - Facultad Regional Tucumán) fue asaltada por la violencia represiva y el 3 de diciembre de 1975 sufrió el secuestro y desaparición de trece de sus miembros, incluyendo su Decana y el presidente del centro de estudiantes (Pucci, 2009 : 249 y 256).

El accionar de los «grupos de tareas» se asienta en tres elementos claves : secreto (garantizaba la eficiencia y agudizaba el clima de terror colectivo), clandestinidad (se buscaba impedir la identificación de los secuestradores y del destino final de las víctimas) e impunidad (garantiza los elementos anteriores) (ICB, 1991 : 39-40). En los operativos de secuestro generalmente se creaban «zonas francas» o zonas liberadas para el accionar, en sincronía con el apagón de las luces en la zona. Así es como la muerte intentaba por momentos convertirse en algo nocturno, silencioso y cotidiano. Eudoro, uno de los personajes de la novela le refiere a Globe:

\section{Vos no sabés lo que fue Tucumán en esos años de la dictadura. Apagaban las luces de la ciudad, todos nos encerrábamos en las casas, y sólo escuchábamos los "Unimog", los camiones del Ejército, y los helicópteros pasar a gran velocidad por la ciudad. [...] A veces alguien comentaba que en la madrugada, un vecino de la cuadra había sido sacado a culatazos, junto a su mujer embarazada, por un grupo de encapuchados. Pero no se sabía nada en concreto, sólo rumores. Después, sí, sabríamos que eso era habitual : las purgas urbanas de gente cuyo único pecado era pensar distinto... (Wilde, 2000 : 102)}

Pero los rumores o la ficción tiene algo de cierto y acaso ese hombre fuera Arcadio Romero Reyes a quien se llevaron el día 20 de julio de 1977 a las 3 de la madrugada. Su mujer estaba embarazada de seis meses y no sólo la golpearon y la patearon a ella (mientras le gritaban «te vamos a hacer parir tu hijo a patadas»), sino que también hicieron lo mismo con las otras hijas de tres y dos años que se aferraban a los pies de su padre (ICB, 1991 : 47-48). O tal vez es el caso de Marta López, quien tenía seis meses de embarazada cuando fue golpeada y secuestrada, junto a otros integrantes de su familia, en la madrugada del 27 de febrero de 1976 por un grupo de 15 a 20 personas armadas y encapuchadas. Luego fue liberada pero del resto de su familia no se volvió a saber más nada (ICB, 1991 : 85).

Al asumir Bussi, en la madrugada del 24 de marzo de 1976, como gobernador militar de la provincia se establece una continuidad macabra entre democracia y dictadura, que se reeditará, cuando Bussi sea elegido a través del voto, como representante provincial, nacional y, luego, como gobernador de la provincia en 1995. En 1976, en la madrugada del 24 de marzo, ordena la desaparición de figuras clave de la vida política y social de la provincia : Eduardo Tenreyro (Secretario General de la Gobernación), José Chebaia (Secretario de Estado de Planeamiento), Francisco Isauro Arancibia (docente y dirigente del gremio ATEP de docentes), Guillermo Vargas Aignasse (Senador provincial) (ICB, 1991 : 14-22). Nuevamente 


\section{Las muertes de Bussi}

El jueves 24 de noviembre de 2011, en San Miguel de Tucumán, murió Antonio Domingo Bussi. El mismo día de su muerte se iniciaba un nuevo juicio en el que Bussi debía responder por la violación de domicilio, privación ilegítima de libertad y homicidio agravado, en perjuicio de Juan Carlos Aguirre y Margarita Susana Azize Weiss. En el año 2008 ya había sido condenado a cadena perpetua por la desaparición y de Guillermo Vargas Aignasse, hecho ocurrido en la madrugada del 24 de marzo de 1976.

Mientras tanto en la ficción, los mismos habitantes que alabaron el trabajo de limpieza de Bussi y luego lo votaron como gobernador en las elecciones de 1995, ahora lo han asesinado y lo olvidaron. Entonces, el problema no es Bussi. Así, como para muchos no importa el muerto que ahora es Bussi, tampoco les importan los otros muertos. Howard Globe en una entrevista consigue un testimonio clave de un policía:

\footnotetext{
-Yo no sé quién le paga a usted, ni me interesa -comenzó a decir el comisario, tras echar una ampulosa bocanada-, pero creo que éste es un crimen que ya no le interesa a nadie...[...] Hay mucha gente que está contenta con la muerte de Bussi, incluso sus más fanáticos chupamedias... Aquí no hay nada raro, está clarito : Bussi fue. El resto no tiene importancia, vea, ahora ya nadie quiere acordarse de Bussi. Ni yo, que lo he votado. (Wilde, 2000 : 135)
}

A partir de la constitución de una memoria desarmada (esta afirmación es un oxímoron de lo lingüístico pero no lo es de lo real), fragmentada, es como Bussi puede aparecer nuevamente en escena, ahora en elecciones democráticas y sostener una imagen positiva en el electorado tucumano. Los procesos de resistencia social de las décadas anteriores son borrados o leídos como desorden, eliminados a partir del nuevo orden del autoritarimo y la represión. Se producen dos procesos contiguos que pueden ser descriptos como la aplicación de un nuevo «orden de la memoria» para recordar «la memoria del orden» (2001 : 141). Esto se apoya también en un quiebre muy fuerte de la «narrativa histórica» que no permite reconstruir procesos históricos (2001 : 125). Bussi es transformado entonces, recordado como un restaurador del orden, como el hombre que vino a devolver a Tucumán, la limpieza, la decencia, el progreso y el saneamiento. Se ha producido un «parcelamiento de la memoria» y esta fragmentación permite al individuo ejercer sin límites la indiferencia y la irresponsabilidad frente a su historia reciente, a su propio pasado (Marcos, 2006 : 114). Este proceso de memoria se vincula con el fortalecimiento de los perfiles autoritarios, vinculados ya en democracia con el clientelismo y el paternalismo (2006: 114).

\section{Voto con olvido}

Durante los días del "Operativo Independencia” Bussi inauguraba estatuas, complejos deportivos, tapiaba villas miseria y, por las noches, se dedicaba a coordinar los operativos represivos. El fraccionamiento de lo real a través del ocultamiento y la amnesia posibilitó el despliegue de la violencia y de las retóricas 
del olvido. Esta violencia casi matriz de la sociedad tucumana, se puede vincular también con una vocación autodestructiva del tucumano : «los tucumanos seguimos siendo enemigos de los tucumanos ; incrédulos, despectivos y aún despreciativos con nosotros mismos» (Pucci, 2007 : 248). Este impulso de autodestrucción se puede vincular con la supuesta aplicación del "voto castigo". Sobre el voto a Bussi en las elecciones de 1995 se escribe en la novela:

Su triunfo en las urnas en julio de 1995, con el 43\% de los sufragios y el 69\% de las expectativas favorables, fue el voto castigo de un pueblo sin trabajo, defraudado, y con hambre de esperanzas [...]. Pero es casi seguro que existen otros motivos ocultos, perdidos en el inconsciente colectivo, que sustentan este voto al ex dictador. (Wilde, 2000 : 37)

De la autodestrucción violenta de los cuerpos y de la memoria se llega al silencio. El autor intenta plantear en la novela que Tucumán es una ciudad, que al igual que el país, está acosada por la amnesia, existe una vocación de olvido en cada gesto esquivo. El olvido silencioso es frágil y tranquilo. La democracia no es una barrera de cambio total, existen permanencias, no es posible dictaminar un corte rotundo. La persistencia de figuras autoritarias que se presentan a elecciones enuncia la gran complejidad de la democracia, que más que una forma, vive en sus prácticas, las que verdaderamente le brindan sentido.

Cuando empecé a trabajar sobre el "Tucumanazo", me interesaba entender por qué la gente había votado a Bussi y entonces la directora de mi trabajo me sugirió empezar por los años 70, tratar de entender la historia previa de la provincia.

Creo que muchas de las explicaciones antecedentes a mi trabajo sobre Bussi, desconocían o no incorporaban la historia previa, de los veinte años anteriores para comprender el cuadro político o económico de la provincia y la historia de luchas populares y de represión política.

[...] Y con respecto al "voto castigo" había una fracción de los votantes intermitentes de los cuales el castigo o el rechazo a otros políticos estaba presente, pero en el núcleo duro de los votantes a Bussi estaba presente el voto positivo, aquellos que creían que iba a mejorar la vida en la provincia, como la había mejorado en los años 70. En los cuales se activaba una memoria positiva de la actuación de Bussi durante la represión.14

Los apoyos cosechados por Bussi cuando estuvo al frente del "Operativo Independencia” y luego como Gobernador militar, se reiteran en gran medida en cada una de las elecciones en las que participa. Beneficiado por las Leyes de Obediencia Debida y Punto Final que promovían el olvido y la supuesta "reconciliación", en 1987, Bussi se presenta por primera vez a elecciones y es elegido Diputado nacional. Al año siguiente funda su propio partido, Fuerza Republicana, y en las elecciones de 1991 se presenta como candidato a gobernador y es derrotado por un estrecho margen por el cantante Ramón "Palito" Ortega. Sin embargo, en las elecciones provinciales de 1995 es proclamado gobernador de la provincia.

Durante su mandato como gobernador militar, Bussi contaba con 6 millones de dolares mensuales de los cuales nunca rindió cuentas (Marcos, 2007 : 56). Posteriormente, como gobernador democrático ocultó cuentas millonarias en bancos de Suiza y cuando los periodistas lo interrogaron sobre la cuestión aseveró : « Ni lo niego ni lo afirmó » (La Gaceta, 24 de noviembre de 2011). Bussi llevó así la palabra a su extrema indigencia. Tiempo después, Bussi llorará ante las cámaras cuando se hagan públicos los informes de la justicia internacional que demuestran la 
existencia de las cuentas. Posteriormente, en 1999, es elegido nuevamente Diputado nacional pero la Cámara recusa sus pliegos, y en 2003, luego de ser votado como Intendente de la Capital, tampoco puede asumir su cargo. Los episodios de desfalco y la mentira parecían haber sido olvidados. Y luego recordados.

\section{Conclusiones : preguntas para armar el presente}

El trabajo activo del lector/oyente con los cruces genéricos y la forma de la novela pone de relieve la condición de « contemporaneidad » del autor con los sucesos, lo que genera la incompletitud de la visión y el permanente desarrollo de la historia que busca su continuación. El pasado revive desde el presente, resiste en la reescritura, pervive como una marca y como una necesidad de memoria:

El autor observa desde su incompleta contemporaneidad -con toda la complejidad y plenitud de ésta ; además, es como si él mismo se encontrase en la tangente de la realidad que está representando. Esa contemporaneidad desde la cual observa el autor, incluye en sí misma, en primer lugar, el campo de la literatura - pero no solo el de la contemporánea, en el sentido estrecho de la palabra, sino también el del pasado que continúa viviendo y renovándose en la contemporaneidad-.(Bajtín, 1989: 406)

Ernesto Wilde y el alter ego Howard Globe, se ubican en el presente, en la contemporaneidad de los sucesos ; escriben y leen la ciudad desde una tangente, desde un lugar incómodo, como si fueran extranjeros que llegan a un lugar y tratan de comprender. Aparecen en el relato fragmentos, frases, datos, estadísticas ante el lector/oyente que debe asumir como una actividad la búsqueda de una forma. Pero la novela cambia con la introducción de nuevas pistas y el lector debe reorganizarlas. Alli permanece algo presente, como una marca de agua sobre cada uno de los sucesos relatados : la interrogación se sigue escuchando, la búsqueda de las razones no se detiene. Las preguntas persisten y se sostienen, impulsan las búsquedas de sentido. La ficción se convierte en una forma que enmarca la pregunta y le brinda atisbos para una posible respuesta frente a la incertidumbre interminable. Es preciso entonces rearmar esa "narrativa histórica", poner en diálogo las diversas trayectorias para tramar nuevamente una historia de la ciudad y de la provincia. Tanto la novela como la investigación histórica sobre estos procesos intentan poner a funcionar una serie de interrogantes fundamentales. Otro de los elementos compartidos entre la novela de Ernesto Wilde y las investigaciones de Emilio Crenzel y Dolores Marcos, es el intento constante de demostrar las relaciones y los apoyos existentes entre Bussi y el entonces presidente Carlos Saúl Menem. El interrogante es : ¿Cómo puede un Presidente democrático apoyar y avalar a un genocida?. En la novela se denomina a la presidencia de Menem como el «Sultanato de la impunidad». Las preguntas pueden ser el mejor antídoto en contra de las conciencias del olvido, las preguntas siempre incomodan, esperan, nos aguardan. Plantean la posibilidad y la necesidad de respuestas, pero otorgadas a través de una relación de hechos, de un relato de vínculos.

35 Y como la contemporaneidad reclama la incompletitud de los hechos y del relato, la historia continuó. Antonio Domingo Bussi fue degradado y expulsado del Ejército de forma deshonrosa, condenado a Prisión Perpetua por el secuestro y la desaparición del político Guillermo Vargas Aignasse, hecho sucedido el 24 de marzo 
de 1976. El 24 de noviembre de 2011, Bussi murió en la ciudad de San Miguel de Tucumán juzgado y condenado. Aunque no cumplió su condena en una cárcel común sino en un barrio privado con una cancha de golf a su alcance. En el año 2012, huesos encontrados en el "Pozo de Vargas", una fosa común empleada durante el "Operativo Independencia", fueron identificados como restos de Guillermo Vargas Aignasse. Desde ese momento dejaba de ser un desaparecido para transformarse en un asesinado por Bussi. La historia señalaba el término de esa impunidad. Aunque las preguntas siguen convocando la escritura.

\section{Bibliografia}

\section{Fuentes orales}

Entrevistas realizadas por el autor a:

Roberto Pucci. 13 de abril de 2012, San Miguel de Tucumán.

Carlos Alsina. 24 de octubre de 2012, San Miguel de Tucumán.

Emilio Crenzel. 16 de abril de 2013, San Miguel de Tucumán.

\section{Prensa}

Diario La Gaceta. Tucumán

Diario La Nación. Buenos Aires

\section{Bibliografía}

Alsina, Carlos, Dramaturgia de Carlos María Alsina. Hacia un teatro esencial, Buenos Aires : Instituto Nacional del Teatro, 2006.

Alsina, Carlos, Teatro, Ética y Política. Historia del Teatro Tucumano. El bussismo. Complicidades, silencios y resistencias, Buenos Aires - Los Ángeles : Editorial Argus-a, 2013.

Artese, Matías ; Roffinelli, Gabriela, Responsabilidad civil y genocidio. Acciones y declaraciones públicas durante el Operativo Independencia, Buenos Aires : Tientos, 2007.

Bajtín, Mijail, Teoría y estética de la novela. Trabajos de investigación, Madrid : Taurus, 1989.

Bloch, Marc, Introducción a la historia, México : FCE, 2000.

Camus, Albert, El hombre rebelde, Buenos Aires : Losada, 2003.

Comisión Bicameral, Informe de la Comisión Bicameral Investigadora de las Violaciones de los Derechos Humanos en la Provincia de Tucumán 1974-1983, Salamanca : IEPALA (Instituto de Estudios Políticos para América Latina y África), 1991.

CONADEP, Nunca más. Informe de la Comisión Nacional sobre la Desaparición de Personas, Buenos Aires : Eudeba, 2013.

Crenzel, Emilio, El tucumanazo, Tucumán : UNT, 1997.

Crenzel, Emilio, Memorias enfrentadas : el voto a Bussi en Tucumán, Tucumán : UNT, 2001.

Crenzel, Emilio, "El Operativo Independencia en Tucumán”, Fabiola Orquera (comp.) : Ese ardiente jardín de la República : Formación y desarticulación de un "campo" cultural : Tucumán, 1880-1975, Córdoba : Alción Editora, 2010.

De Certeau, Michel, La escritura de la historia, México : Universidad Iberoamericana, 1993.

De Riz, Liliana, Historia argentina 8. La política en suspenso : 1966-1976, Buenos Aires : Paidós, 2007.

Flawiá de Fernández, Nilda ; Steimberg, Olga Ruth, Narradores argentinos contemporáneos, Tucumán : Ed. El Graduado, 1984.

Foguet, Hugo, Pretérito Perfecto, Buenos Aires : Legasa, 1983.

García Canclini, Néstor, El mundo entero como lugar extraño, Buenos Aires : Gedisa, 2014.

Halbwachs, Maurice, La memoria colectiva, Buenos Aires : Miño y Dávila Editores, 2011. 
Jitrik, Noé, Historia e imaginación literaria. Las posibilidades de un género, Buenos Aires : Biblos, 1995 .

Lagmanovich, David, La literatura del Noroeste argentino, Rosario : Ed. Biblioteca, 1974.

Lagmanovich, David, Ensayos sobre la cultura de Tucumán, Tucumán : Fund. Miguel Lillo, 2010.

Marcos, Dolores, Asedio a la democracia. Perfiles del autoritarismo en el NOA, Tucumán : UNT, 2006.

Martínez, Tomás Eloy, "Historia y ficción : dos paralelas que se tocan", Karl Kohut (ed.) : Literaturas del Río de la Plata hoy : de las utopías al desencanto : [actas del Simposio Internacional "Literaturas del Río de la Plata hoy. Máscaras regionales en Rostros Metropolitanos" del 6 al 8 de mayo 1993], Madrid : Iberoamericana, 1996.

Nassif, Silvia, Tucumanazos : Una huella histórica de luchas populares : 1969-1972, Tucumán : UNT, 2012.

Nassif, Silvia, Tucumán en llamas. El cierre de los ingenios y la lucha obrera contra la dictadura (1966-1973), Tucumán : UNT, 2016.

Nofal, Dardo, Una lágrima por el cóndor, Buenos Aires : Corregidor, 1995.

Novaro, Marcos ; Palermo, Vicente, Historia Argentina 9 : La dictadura militar 1976/1983 : del golpe de Estado a la restauración democrática, Buenos Aires : Paidós, 2013.

Orphée, Elvira, Aire tan dulce, Buenos Aires : Bajo La Luna, 2009.

Pucci, Roberto, Historia de la destrucción de una provincia : Tucumán 1966, Buenos Aires : Ediciones del Pago Chico, 2007.

Pucci, Roberto, “Tucumán, 1975. La guerrilla y el terrorismo de estado antes del golpe militar", R. Pucci y L. Bonano (comp.) : Autoritarismo y dictadura. Estudios sobre cultura, política y educación, Buenos Aires : Ed. Catálogos, 2009.

Pucci, Roberto, "Historia y ficción literaria : identidades y oposiciones", L. Massara, R. Guzmán, A. Nallim : La literatura del Noroeste Argentino : reflexiones e investigaciones, Jujuy : UNJu. Volumen II, 2012.

Pucci, Roberto, Pasado y presente de la Universidad de Tucumán. Reformas, dictaduras y populismo neoliberal, Buenos Aires : Lumiere, 2012.

Ricoeur, Paul, La memoria, la historia, el olvido, Buenos Aires : FCE, 2008.

Rosenzvaig, Eduardo, La oruga sobre el pizarrón : Isauro Arancibia, maestro, Buenos Aires : Cartago Ediciones, 2011.

Rosenzvaig, Eduardo, La cuenta suiza, Buenos Aires : Ed. Armas de la Crítica, 2000.

San Martino de Dromi, María Luisa, Historia Política Argentina (1955-1988), (2 tomos), Buenos Aires : Ed. Astrea, 1988.

White, Hayden, La ficción de la narrativa. Ensayos sobre historia, literatura y teoría, 19572007, Buenos Aires : Eterna Cadencia, 2011.

Wilde, Ernesto, Saldos y retazos, Buenos Aires : Ed. Cimarrón, 1993.

Wilde, Ernesto, El día que mataron a Bussi, Tucumán : UNT, 2000.

\section{Notas}

1 «A la provincia de Tucumán le cupo el siniestro privilegio de haber inaugurado la "institución" Centro Clandestino de Detención como una de las herramientas fundamentales del sistema de represión montado en la Argentina» (CONADEP, 2013 : 216)

2 Cfr. CONADEP, 2013 ; Pucci, 2009 ; Crenzel, 2010 ; Novaro y Palermo, 2013.

3 A partir de un proyecto de ley del entonces gobernador de Tucumán, Fernando Pedro Riera, se promulgó y se publicó en el Boletín Oficial, el 22 de febrero de 1984, la Ley Provincial 5599 que creaba la Comisión Bicameral de Derechos Humanos que tenía como fin «contribuir al esclarecimiento de los hechos relacionados con la desaparición de personas y los violatorios de los derechos humanos ocurridos en la provincia» entre los años 1974 y 1983. El Informe fue concluido en los años siguientes y publicado recién en 1991. 
4 Desde ahora en adelante se consignarán las citas del Informe con las siglas ICB.

5 Cfr. Pucci, 2007 ; Nassif, 2012, 2016.

6 Cfr. Crenzel, 1997 ; Nassif, 2012, 2016.

7 Ernesto Wilde (breve bio-bibliografía) : Nació el 1 de enero de 1950 en la ciudad de San Miguel de Tucumán. Escritor y periodista, trabajó en el diario La Gaceta y en El periódico de Tucumán. Publicó los libros de poemas Sobre la ladera del Volcán (1972), El habitante saqueado (1988) y Tumbacabezas (1996); y las novelas Saldos y Retazos (1993) y El día que mataron a Bussi (2000). Murió el martes 31 de mayo del 2011 en la ciudad de San Miguel de Tucumán.

8 Se pueden mencionar las novelas y los cuentos de Hugo Foguet, Dardo Nofal, Eduardo Rosenzvaig, entre otros.

9 Antonio Domingo Bussi, nació el 17 de enero de 1926 en Victoria, Entre Ríos. A los 17 años ingresa al Colegio Militar. Su primera estadía en Tucumán la realiza al cumplir funciones como comandante del Regimiento 19 de Infantería. En 1969 integró la segunda comisión de observadores argentinos en Vietnam y en Estados Unidos se entrenó en tácticas de contrainsurgencia. En 1975 es ascendido a general de brigada y se hace cargo del "Operativo Independencia”. En 1981, Leopoldo Galtieri le pidió el retiro de la fuerza (Marcos, 2006 : 53). Murió en San Miguel de Tucumán el 24 de noviembre de 2011. Acerca de la figura de Bussi cfr. Pucci, 2009 ; Crenzel, 2001 ; Marcos, 2006 ; Rosenzvaig, 2000 ; Santillán, 2006.

10 Entrevista al dramaturgo Carlos Alsina. Realizada por el autor el 24 de octubre de 2012, San Miguel de Tucumán.

11 Entrevista al historiador Roberto Pucci. Realizada por el autor el 13 de abril de 2012, San Miguel de Tucumán.

12 Numerosas figuras claves de la represión en estas décadas y del "Proceso de Reorganización Nacional" hicieron sus "primeras armas" en Tucumán : Luciano Benjamín Menéndez, Jorge Rafael Videla, Alberto Villar, entre otros.

13 Cuando Amado Juri cumplía funciones como Jefe de Policía en la provincia firmó la cédula de identidad de Ricardo Klement, pseudónimo del jerarca nazi Adolf Eichmann.

14 Entrevista al sociólogo Emilio Crenzel. Realizada por el autor el 16 de abril de 2013, San Miguel de Tucumán.

\section{Para citar este artículo}

Referencia electrónica

Máximo Hernán Mena, « Los quiebres del recuerdo: entre democracia y dictadura en la Argentina », Amerika [En línea], 15 | 2016, Publicado el 17 diciembre 2016, consultado el 27 diciembre 2016. URL : http://amerika.revues.org/7700

\section{Autor}

\section{Máximo Hernán Mena}

Universidad Nacional de Tucumán - IILAC, CONICET

maxismena@hotmail.com

\section{Derechos de autor}

(c) Tous droits réservés 